\title{
ARTIGO
}

\section{A inobservância do princípio da proteção ao trabalhador pela reforma trabalhista}

The non-respect of the principle of the protection of workers by the labor reform

\section{Eduardo Baptista Vieira ${ }^{1}$}

RESUMO: $O$ artigo apresenta a inobservância do princípio da proteção ao trabalhador pela reforma trabalhista do Brasil, como resultado de pesquisa bibliográfica e de análise acerca da Lei ${ }^{\circ} 13.467$, de 13 de julho de 2017, conhecida como reforma trabalhista. Inicia-se o estudo com conceitos de princípios jurídicos e apresentando princípios constitucionais e específicos do Direito do Trabalho, especialmente o conceito do princípio da proteção ao trabalhador. O princípio da proteção ao trabalhador, conforme entendimento doutrinário, é constituído pelo princípio da norma mais favorável ao trabalhador, pelo princípio da condição mais benéfica ao trabalhador e pelo princípio do in dubio pro operario, e é considerado o mais significativo da estrutura do Direito do Trabalho. Algumas alterações implementadas na legislação do trabalho pela reforma trabalhista não observaram o princípio da proteção ao trabalhador, fato que deverá repercutir tanto na execução como na interpretação da norma trabalhista brasileira, diminuindo a proteção ao trabalhador, característica típica do Direito do Trabalho.

Palavras-chave: Lei $\mathrm{n}^{\circ} 13.467 / 2017$; princípio protetivo; princípio da norma mais favorável; princípio da condição mais benéfica; princípio do in dubio pro operario; diminuição da proteção ao trabalhador.

ABSTRACT: The article presents the non-observance of the principle of worker protection by the Brazilian labor reform, as a result of a bibliographical research and analysis of Law No. 13467 of July 13, 2017, known as labor reform. It begins the study with concepts of legal principles and presenting constitutional and specific principles of

1 Auditor-Fiscal do Trabalho. Especialista em Direito do Trabalho e Previdenciário pelo Centro Universitário de Brasília - UNICEUB. Especialista em Gestão Pública pelo Instituto IMP de Brasília. Bacharel em Administração pela Universidade Federal da Bahia - UFBA. Bacharel em Comunicação Social pela Universidade Católica de Salvador - UCSAL. 


\section{Eduardo Baptista Vieira}

Labor Law, especially the concept of the principle of worker protection. The principle of worker protection, according to doctrinal understanding, is constituted by the principle of the most favorable norm to the worker, by the principle of the most beneficial condition to the worker and by the principle of the in dubio pro operario, and is considered the most significant of the structure of the Law of the Job. Some changes implemented in labor legislation by the labor reform did not observe the principle of worker protection, a fact that should affect both the execution and the interpretation of the Brazilian labor norm, reducing worker protection, typical feature of Labor Law.

Keywords: Law No.13467/2017; protective principle; principle of the most favorable standard; principle of the most beneficial condition; principle of in dubio pro operario; reduction of worker protection.

\section{INTRODUÇÃO}

O presente artigo estuda o princípio da proteção ao trabalhador e a reforma trabalhista, sancionada, pelo Brasil, em 13 de julho de 2017, analisando a adequação de novos dispositivos da legislação do trabalho perante a lógica do princípio protetivo.

Utilizou-se, na pesquisa, da literatura clássica à atual do Direito do Trabalho brasileiro. Dentre os autores estão Alice Monteiro de Barros, Amauri Mascaro Nascimento, Arnaldo Sussekind, Carlos Henrique Bezerra Leite, Mauricio Godinho Delgado, Sergio Pinto Martins e Vólia Bomfim Cassar.

A temática proposta é de relevância científica e social, uma vez que o Direito do Trabalho está em constante debate no campo político, jurídico, administrativo e acadêmico. O trabalho humano é, em regra, indissociável da vida humana. De acordo com o Instituto Brasileiro de Geografia e Estatística - $\mathrm{IBGE}^{2}$, a força de trabalho brasileira é de 105,4 milhões de pessoas.

Inicialmente, foram pesquisados conceitos de princípios jurídicos, os princípios constitucionais trabalhistas e os princípios específicos do Direito do Trabalho.

Depois, estudou-se o princípio da proteção ao trabalhador, o qual, conforme entendimento doutrinário, é formado pelo princípio da norma mais favorável ao trabalhador, pelo princípio da condição mais benéfica ao trabalhador e pelo princípio

2 BRASIL. Instituto Brasileiro de Geografia e Estatística. Indicadores IBGE. Pesquisa Nacional por Amostra de Domicilios Contínua. Trimestre Móvel Set. - Nov. 2018. Disponível em <https://biblioteca.ibge.gov.br/visualizacao/periodicos/3086/pnacm_2018_nov.pdf > Acesso em: 30 jan. 2019. 
do in dubio pro operario. Em seguida, pesquisou-se sobre o processo e os fundamentos da reforma trabalhista brasileira.

Finalmente, o artigo analisou dispositivos da reforma trabalhista que se relacionam com o princípio da proteção ao trabalhador, constatando a inobservância do princípio protetivo em alterações implementadas pela nova legislação do trabalho, o que reduz a proteção ao trabalhador, característica típica do Direito do Trabalho, tanto na execução da lei como na interpretação da norma trabalhista.

\section{PRINCÍPIOS CONSTITUCIONAIS E ESPECÍFICOS DO DIREITO DO TRABALHO}

A palavra princípio origina-se do latim principium ou princippi, significando origem, começo ou base (MARTINS, 2014).

Sussekind (2002, p. 107) ensina que princípios são "enunciados genéricos que devem iluminar tanto a elaboração das leis, a criação de normas jurídicas autônomas e a estipulação de cláusulas contratuais, como a interpretação e a aplicação do direito".

Segundo Cassar (2014, p. 153), “princípio é a postura mental que leva o intérprete a se posicionar desta ou daquela maneira. Serve de diretriz, de arcabouço, de orientação para que a interpretação seja feita de uma certa maneira e, por isso, tem função interpretativa".

Nascimento (2014, p. 119) argumenta que "os princípios jurídicos são valores que o Direito reconhece como ideias fundantes do ordenamento jurídico, dos quais as regras jurídicas não devem afastar-se para que possam cumprir adequadamente os seus fins".

\section{Princípios Constitucionais do Direito do Trabalho}

Os princípios constitucionais aplicáveis ao Direito do Trabalho, de acordo com Cassar (2014), são o respeito à dignidade da pessoa humana; os valores sociais do trabalho; a livre-iniciativa; a inviolabilidade do direito à vida, à liberdade, à igualdade; a anterioridade legal; que ninguém será submetido à tortura nem a tratamento desumano ou degradante; a livre manifestação do pensamento; o direito à indenização por dano moral, material ou à imagem; a liberdade de consciência e de crença; a isonomia de tratamento; a inviolabilidade à intimidade, à vida privada, à honra e à imagem; o livre exercício de qualquer trabalho ou ofício; o direito à informação; a livre reunião pacífica; o direito à associação para fins lícitos; que 


\section{Eduardo Baptista Vieira}

ninguém é obrigado a associar-se ou a permanecer associado; a legitimidade das associações; que a lei não excluirá do judiciário lesão ou ameaça de direito; o respeito ao direito adquirido, ao ato jurídico perfeito e à coisa julgada; o direito ao contraditório e ampla defesa; a justiça social; a função social da empresa; e a busca do pleno emprego.

Barros (2010) esclarece que os princípios constitucionais são entendidos, por alguns autores, como direito positivo, portanto, com plena eficácia normativa.

\section{Princípios específicos do Direito do Trabalho}

Segundo Barros (2010, p. 180), os princípios peculiares do Direito do Trabalho "inspiram o ordenamento jurídico-trabalhista, de acordo com critérios distintos não encontrados em outros ramos do Direito", tendo a função de informar ao legislador e orientar ao julgador para o correto exercício das suas atividades. A autora considera que os princípios específicos do Direito do Trabalho são o da proteção ao trabalhador, o da primazia da realidade, o da irrenunciabilidade de direitos e o da continuidade da relação de emprego.

Delgado (2014) elenca como princípios do Direito Individual do Trabalho o da proteção ao trabalhador, o da norma mais favorável ao trabalhador, o da imperatividade das normas trabalhistas, o da indisponibilidade dos direitos trabalhistas, o da condição mais benéfica ao trabalhador, o da inalterabilidade contratual lesiva ao trabalhador, o da intangibilidade salarial, o da primazia da realidade e o da continuidade da relação de emprego.

Para Cassar (2014), os princípios específicos do Direito do Trabalho são o princípio da prevalência da condição mais benéfica ao trabalhador, o princípio da norma mais favorável ao trabalhador, o princípio do in dubio pro operario, o princípio da primazia da realidade, o princípio da intangibilidade e da irredutibilidade salarial, o princípio da continuidade da relação de emprego, o princípio da continuidade da empresa ou função social da empresa, o princípio da inalterabilidade contratual em prejuízo ao obreiro, o princípio da boa-fé, e o princípio da alheabilidade.

Verifica-se que o Direito do Trabalho está sustentado em uma normatização jurídica constituída de princípios específicos, que servem para orientar a concepção, a aplicação e a interpretação das leis trabalhistas.

\section{O PRINCÍPIO DA PROTEÇÃO AO TRABALHADOR}


Segundo Sussekind (2002), o Direito do Trabalho pressupõe a desigualdade entre as partes. Dessa forma, a legislação trabalhista visa corrigir essa desigualdade através de uma desigualdade de natureza jurídica. O princípio da proteção ao trabalhador erigese como o mais relevante e essencial para o Direito do Trabalho, seja na construção, interpretação ou aplicação da lei. A raiz sociológica justrabalhista é a proteção social dos trabalhadores.

Cassar (2014, p. 169) destaca que a diretriz principal do Direito do Trabalho é "a proteção do trabalhador, uma vez que o empregado não tem a mesma igualdade jurídica que o empregador, como acontece com os contratantes no Direito Civil".

Cassar (2014, p. 169) explica que a razão de existir do Direito Laboral é o alcance de "uma verdadeira igualdade substancial entre as partes e, para tanto, necessário é proteger a parte mais frágil desta relação: o empregado". Assim, instituiu-se o princípio protetivo, que objetiva equilibrar a relação entre o empregado e o empregador. A autora ensina, ainda, que esse princípio se caracteriza pela intervenção do Estado nas relações empregatícias, limitando a autonomia da vontade das partes.

Sussekind (2002, p. 111) leciona que o princípio da proteção ao trabalhador "resulta das normas imperativas e, portanto, de ordem pública, que caracterizam a intervenção básica do Estado nas relações de trabalho, visando a opor obstáculos à autonomia da vontade". Em decorrência desse princípio surgem o princípio in dubio pro operario; o princípio da norma mais favorável; o princípio da condição mais benéfica; o princípio da primazia da realidade; o princípio da inalterabilidade contratual em prejuízo ao trabalhador; e os princípios da integralidade e da intangibilidade, que protegem o salário.

Segundo Martins (2014), o princípio da proteção alcança os trabalhadores empregados e não todos os trabalhadores, podendo ser desmembrado em três: in dubio pro operario, aplicação da norma mais favorável ao trabalhador e a aplicação da condição mais benéfica ao obreiro.

Em uma interpretação mais ampla, Delgado (2014, p. 184) explica que a proteção ao trabalhador alcança, em regra, todos os princípios especiais do Direito Individual do Trabalho.

Ela abrange, essencialmente, quase todos (senão todos) os princípios especiais do Direito Individual do Trabalho. Como excluir essa noção do princípio da imperatividade das normas trabalhistas? Ou do princípio da inalterabilidade contratual lesiva? Ou da proposição relativa à continuidade da relação de emprego? Ou da noção genérica de 
despersonalização da figura do empregador (e suas inúmeras consequências protetivas ao obreiro)? Ou do princípio da irretroação das nulidades? E assim sucessivamente. Todos esses outros princípios especiais também criam, no âmbito de sua abrangência, uma proteção especial aos interesses contratuais obreiros, buscando retificar, juridicamente, uma diferença prática de poder e de influência econômica e social apreendida entre os sujeitos da relação empregatícia.

Segundo Cassar (2014), não há consenso na doutrina se o princípio da proteção do trabalhador seria gênero de todos os princípios do Direito do Trabalho, ou apenas dos princípios da norma mais favorável ao trabalhador, da condição mais benéfica ao trabalhador, e do in dubio pro operario. Cassar (2014, p. 170) explica que "a doutrina majoritária, seguindo a orientação de Américo Plá Rodriguez, defende que o princípio da proteção é gênero que comporta as três espécies acima”.

Apesar da larga abrangência do princípio protetivo, observa-se que a sua base principiológica é formada pelos princípios da norma mais favorável ao trabalhador, da condição mais favorável ao trabalhador e do in dubio pro operario. Consequentemente, são esses os princípios nucleares do princípio da proteção ao trabalhador e que serão analisados perante as alterações impostas pela reforma trabalhista.

\section{Princípio da norma mais favorável ao trabalhador}

De acordo com o princípio da norma mais favorável, o intérprete deverá optar pela regra mais favorável ao trabalhador no instante da elaboração da regra; quando houver confronto entre regras concorrentes; e na interpretação das regras jurídicas.

Delgado (2018) leciona que o caput do art. $7^{\circ}$ da Constituição, ao afirmar que "São direitos dos trabalhadores urbanos e rurais, além de outros que visem à melhoria de sua condição social: [...]", estabelece o objetivo de elevar as condições de pactuação da força de trabalho no sistema socioeconômico. O princípio da norma mais favorável é um dos que mais cumprem essa finalidade, pois está alinhado à matriz constitucional humanística e social, trazendo consistência ao próprio Estado Democrático de Direito.

Para Leite (2018), o Direito do Trabalho adota a teoria dinâmica da hierarquia das normas trabalhistas porque no topo da pirâmide não está obrigatoriamente a Constituição, mas, sim, a norma mais favorável ao trabalhador. Por entender que a Constituição recepcionou o princípio da norma mais favorável, o autor explica que, 
caso exista uma norma que estabeleça um direito maior entre duas normas aplicáveis a uma situação, a norma que maximize o direito do trabalhador é a que deverá ser escolhida pelo intérprete.

Cassar (2018) ensina que o Direito do Trabalho se difere dos outros ramos do Direito em decorrência do princípio da norma mais favorável ao trabalhador. Enquanto em outras áreas do Direito, se houver conflito de normas, deve-se aplicar a de grau superior ou, se normas de igual hierarquia, deve-se optar pela mais recente ou a especial, contudo, no Direito do Trabalho deverá prevalecer a norma que mais trouxer benefícios ao empregado.

Em outras palavras, segundo Cassar (2018, p. 181), o princípio da norma mais favorável define que "caso haja mais de uma norma aplicável a um mesmo trabalhador, deva-se optar por aquela que lhe seja mais favorável, sem se levar em consideração a hierarquia das normas”.

Como demonstrado (NASCIMENTO; NASCIMENTO, 2018), o princípio da norma mais favorável pode assumir três funções. A primeira, a de elaboração das normas jurídicas (que devem ser compensatórias da inferioridade econômica do empregado na relação de trabalho); a segunda, a de definição da hierarquia das normas diante de um conflito normativo (por exemplo, entre lei e convenção coletiva, porquanto o Direito do Trabalho é plurinormativo); e a terceira, a de interpretação das normas jurídicas quando houver obscuridade quanto aos significados dessas normas (para produzir o resultado de acordo com o sentido social do Direito do Trabalho).

\section{Princípio da condição mais benéfica ao trabalhador}

Segundo Cassar (2017), o princípio da condição mais benéfica ou da condição mais favorável ao trabalhador determina que todo tratamento favorável ao empregado, concedido tacitamente e de modo habitual, deverá prevalecer, não podendo ser suprimido porque está incorporado ao patrimônio contratual do obreiro.

Delgado (2018) esclarece que não se trata de contraponto entre normas, mas entre cláusulas contratuais (tácitas ou expressas). O autor argumenta que, tecnicamente, se trata do princípio da cláusula mais benéfica e que, de certa forma, esse princípio é traduzido em manifestação do princípio da inalterabilidade contratual lesiva, igualmente característico do Direito Trabalhista.

Conforme demonstrado (NASCIMENTO; NASCIMENTO, 2018, p. 158), o princípio da condição mais favorável tem a função de: 
[...] resolver o problema da aplicação da norma jurídica trabalhista no tempo, quando a norma cronologicamente posterior modificar ou suprimir um direito previsto pela norma anterior revogada, caso em que, para resguardar os direitos do trabalhador diante das transformações prejudiciais que podem afetá-lo, deve enunciar-se a preservação da condição de trabalho que mais beneficiá-lo, como forma de defesa do seu direito adquirido.

Leite (2018) explica que o princípio da condição mais favorável diz respeito à aplicação da norma trabalhista. $O$ autor cita que se houver cláusula ou condição em norma jurídica preexistente mais benéfica ao trabalhador, mesmo que sobrevenha nova norma versando sobre a mesma disciplina, a condição mais benéfica deverá prevalecer. $\mathrm{O}$ autor reconhece a recepção desse princípio, insculpido no caput do art. $7^{\circ}$, pela Constituição.

Por condição favorável entende-se aquela que não fere as regras do Direito, os seus princípios e os bons costumes. $\mathrm{O}$ intérprete deve levar em consideração o bem-estar do trabalhador, entendido como a saúde mental, física e social do obreiro.

Com efeito, Cassar (2018) leciona que concessões de drogas lícitas como cigarros e bebidas jamais incorporariam o contrato de trabalho do empregado. Por outro lado, a reversão de jornada de trabalho de 12 horas de trabalho por 36 horas de descanso para 08 horas diárias de labor; a alteração espontânea de plano de cargos e salários, também favorável ao empregado, mesmo com prejuízos de alguns dispositivos; e a reversão do trabalho noturno, insalubre ou perigoso, com a supressão dos respectivos adicionais pagos, não afrontam o princípio da condição mais favorável.

\section{Princípio do in dubio pro operário}

Para Cassar (2017), o princípio in dubio pro operario ou in dubio pro misero estabelece que, em caso de dúvida por parte do intérprete, que decorra de uma interpretação razoável e distinta acerca da aplicação de uma norma, ele deverá decidir em favor do trabalhador, a parte mais frágil da relação trabalhista.

Esse é um princípio "de interpretação, significando que, diante de um texto jurídico que possa oferecer dúvidas a respeito do seu verdadeiro sentido e alcance, o intérprete deverá escolher, dentre as hipóteses interpretativas viáveis, a mais benéfica para $\mathrm{o}$ trabalhador" (NASCIMENTO; NASCIMENTO, 2018, p. 158). 
Leite (2018, p. 99) esclarece que esse princípio "auxilia a interpretação da norma trabalhista em prol do trabalhador. Assim, quando se está diante de uma única norma que permita mais de uma interpretação, deve prevalecer aquela que mais favoreça o empregado". Como exemplo, o autor cita a regra contida no art. 10, II, b, do ADCT, da Constituição de 1988, que trata da dispensa arbitrária ou sem justa causa da empregada gestante desde a confirmação da gravidez até cinco meses após o parto.

Observe-se que a expressão desde a confirmação da gravidez confere ao intérprete mais de uma possibilidade, tal qual desde a comunicação da empregada ao empregador, ou desde a apresentação do atestado médico, ou desde a data provável da fecundação. Atraindo a aplicação do princípio in dubio pro operario, a intepretação adequada é a de que a empregada gestante possui estabilidade no emprego desde a data provável da fecundação.

No Direito Processual do Trabalho, conforme Martins (2014), pelo fato do ônus da prova competir a quem fizer as alegações, o princípio do in dubio pro operario é suavizado, pois não basta se fazer meras alegações (allegatio et non probatio quase non allegatio). No processo trabalhista, portanto, havendo dúvida por parte do juiz, ele deverá decidir em favor da parte que não tenha o ônus da prova, e não segundo a diretriz geral do in dubio pro operario.

Em análise da aplicação desse princípio no campo processual trabalhista, Cassar (2018) indica três correntes: a primeira, que argumenta que o princípio do in dubio pro operario deve se limitar a inspirar o legislador processual; a segunda, que sustenta que, além de inspirar o legislador processual, o princípio deve também ser aplicado ao Direito Processual do Trabalho; e a terceira, que acredita que esse princípio, além de influenciar o legislador processual e de ser aplicado em caso de dúvidas na interpretação, deve igualmente ser considerado quando da valoração das provas produzidas processualmente.

Cassar (2018, p. 185) afina-se com Amauri Mascaro, Wagner Giglio e Rodrigues Pinto, ao entender que "a inspiração deve ser anterior ao processo e destina-se apenas ao legislador processual que, antes de confeccionar a lei, influencia-se pelo princípio da proteção ao trabalhador".

Cairo Junior (2012, p. 49) ressalva que "não se pode negar, entretanto, que o caráter protetivo do Direito Material do Trabalho reflete-se no Direito Processual, mesmo porque este último tem como escopo conferir efetividade às regras que compõem o primeiro". 


\section{A REFORMA TRABALHISTA NO BRASIL}

Reformar significa "formar de novo, reconstruir, dar melhor forma, aprimorar, mudar, modificar, alterar" (MARTINS, 2018, p. 22).

A reforma trabalhista não é a primeira promovida na CLT, pontua Martins (2018). Dentre outras, observam-se: o Decreto-Lei no $229 / 1967$, que deu nova denominação ao contrato coletivo de trabalho (convenção ou acordo coletivo de trabalho), além de alterar artigos relativos à contribuição sindical; a Lei $\mathrm{n}^{\circ}$ 5.442/1968, que modificou a redação de vários artigos da CLT; a Lei $\mathrm{n}^{\circ}$ 5.584/1970, que alterou normas da CLT e disciplinou a concessão e prestação de assistência na Justiça do Trabalho; a Lei ${ }^{\circ}$ 6.203/1975, que tratou da transferência de empregados; a Lei $\mathrm{n}^{\circ} 6.204 / 1975$, que versou sobre aposentadoria espontânea do empregado; o Decreto-Lei $\mathrm{n}^{\circ}$ 1.535/1977, que modificou regras de férias; a Lei $\mathrm{n}^{\mathrm{o}} 6.514 / 1977$, que alterou a nomenclatura do capítulo V da CLT para segurança e medicina do trabalho; as Leis $\mathrm{n}^{\circ} 9.957 / 2000$ e $\mathrm{n}^{\circ}$ 9.958/2000, que criaram o procedimento sumaríssimo e instituíram as Comissões de Conciliação Prévia, respectivamente; e a Lei $n^{\circ} 13.015 / 2014$, que alterou recursos do TST.

Antes da aprovação da reforma trabalhista, iniciativas de alteração da CLT tramitavam pelo Congresso Nacional, tal qual o Projeto de Lei $\mathrm{n}^{\circ} 4.962$, que buscava alterar o entendimento de que as condições ajustadas mediante convenção ou acordo coletivo de trabalho prevalecessem sobre a lei, um dos núcleos da reforma trabalhista.

Leite (2018) explica que a reforma trabalhista teve início em dezembro de 2016, com o envio do Projeto de Lei (PL) n ${ }^{0} 6.787 / 2016$ pelo então Presidente da República à Câmara dos Deputados, o qual alteraria as redações ou inseriria disposições concernentes aos artigos 47, 47-A, 58-A, 523-A, 611-A, 634 e 775 da CLT. O PL versava apenas sobre sete artigos da CLT, com ênfase na alteração do art. 611-A, o qual instituiu a prevalência do negociado entre as partes sobre a lei. Contudo, o autor explica que o projeto foi ampliado por um substitutivo, que acrescentou ou modificou 97 artigos da CLT.

Finalmente, em 13 de julho de 2017, a Lei Ordinária $n^{\circ} 13.467$, conhecida como reforma trabalhista, foi sancionada pela presidência, entrando em vigor em 11 de novembro de 2017, após 120 dias de sua publicação oficial. A reforma promoveu alterações na CLT e nas Leis $\mathrm{n}^{\circ}$ 6.019/74 (trabalho temporário), $\mathrm{n}^{\circ}$ 8.036/90 (FGTS) e $\mathrm{n}^{\mathrm{o}} 8.212 / 91$ (custeio da seguridade social). 
Nahas (2017) registra que é difícil conciliar opiniões quanto à reforma aprovada, entretanto, deve-se considerar a dificuldade estrutural brasileira e mundial, haja vista a sociedade atravessar um período de renascimento em meio à crise do pósneoliberalismo, caminhando para a superação de modelos tradicionais em decorrência da hiperglobalização.

Martins (2018), ao analisar a exposição de motivos dos artigos alterados pela Lei $\mathrm{n}^{\circ}$ 13.467/2017, apresenta os fundamentos da reforma trabalhista: diminuição do ativismo judicial; redução do número de ações na Justiça do Trabalho; empregado como detentor de direitos e obrigações (não hipossuficiente); prestígio à negociação coletiva (intervenção mínima do Estado); incentivo ao andamento dos processos trabalhistas; responsabilização processual; adoção da flexibilização trabalhista como visto na Europa (argumento de manutenção de empregos); racionalização processual; e adoção de meios alternativos de conflitos (arbitragem, negociação entre as partes para encerramento contratual).

Para Martins (2018), a nova legislação alterou muito mais artigos da CLT em favor do empregador do que do empregado, e que pode ser observado, em certos casos, a diluição do princípio da proteção ao trabalhador em benefício da proteção do empregador.

\section{A INOBSERVÂNCIA DO PRINCÍPIO DA PROTEÇÃO AO TRABALHADOR PELA REFORMA TRABALHISTA}

\section{Inobservância do princípio da norma mais favorável ao trabalhador}

Veja-se que a alteração no art. 620 da CLT modifica a lógica do princípio da norma mais favorável ao determinar que o acordo coletivo de trabalho sempre prevalecerá sobre a convenção coletiva de trabalho. A redação anterior prescrevia que as condições estabelecidas em convenção, quando mais favoráveis, prevaleceriam sobre as estipuladas em acordo. Não importa mais a convenção apresentar condições mais benéficas aos obreiros, pois, em qualquer caso, valerá o acordo segundo a nova legislação.

Como o princípio da norma mais favorável pressupõe que, havendo mais de uma norma aplicável, o intérprete deve optar pela norma mais benéfica ao obreiro sem considerar a hierarquia normativa, verifica-se que a Lei $\mathrm{n}^{\circ}$ 13.467/2017 não levou em consideração o princípio da norma mais favorável ao trabalhador na alteração promovida. 


\section{Eduardo Baptista Vieira}

Um dos centros da reforma trabalhista é a valorização da negociação coletiva, ou seja, o conceito do negociado entre as partes prevalecer sobre o legislado. A Lei $n^{\circ}$ 13.467/2017 incluiu dois dispositivos na CLT que trazem esse novo paradigma para o Direito do Trabalho brasileiro, quais sejam, o art. 611-A e o art. 611-B.

O art. 611-A da CLT definiu que os temas alcançados pela negociação coletiva são jornada de trabalho (observados os limites constitucionais); banco de horas anual; intervalo intrajornada (respeitado o limite mínimo de 30 minutos para jornadas superiores a 06 horas); Programa Seguro-Emprego (Lei $n^{\circ} 13.189 / 2015$ ); plano de cargos, salários e funções, bem como o enquadramento de funções de confiança; regulamento empresarial; representante dos trabalhadores no local de trabalho; teletrabalho, regime de sobreaviso e trabalho intermitente; remuneração por produtividade (incluídas as gorjetas) e remuneração por desempenho individual; modalidade de registro de jornada de trabalho; troca do dia de feriado; enquadramento do grau de insalubridade; prorrogação de jornada em ambiente insalubre sem licença prévia das autoridades competentes; prêmios de incentivo em bens ou serviços; e participação nos lucros ou resultados da empresa.

O art. 611-B da CLT aponta os direitos que não podem ser negociados, isto é, os limites da negociação coletiva. Conforme esse dispositivo, os temas vedados à negociação coletiva são normas de identificação profissional (inclusive as anotações na carteira de trabalho); seguro-desemprego; valor dos depósitos mensais e da indenização rescisória do FGTS; salário mínimo; valor nominal do $13^{\circ}$ salário; remuneração do trabalho noturno superior a do diurno; proteção do salário (constituindo crime sua retenção dolosa); salário-família; repouso semanal remunerado; remuneração do serviço extraordinário acrescida de, no mínimo, 50\% do valor normal; dias de férias do empregado; gozo de férias com, pelo menos, 1/3 a mais do salário normal; licença-maternidade mínima de 120 dias; licençapaternidade; proteção do mercado de trabalho da mulher nos termos da lei; aviso prévio proporcional ao tempo de serviço, no mínimo, de 30 dias; normas de segurança e saúde do trabalho; adicional de remuneração para atividades penosas, insalubres ou perigosas; aposentadoria; seguro contra acidentes de trabalho a cargo do empregador; ação quanto aos créditos resultantes das relações de trabalho (com prazo prescricional de cinco anos, até o limite de dois anos da extinção do contrato de trabalho); proibição de discriminação salarial e de critérios para admissão do trabalhador com deficiência; proibição de trabalho noturno, perigoso ou insalubre a menores de 18 anos e de qualquer trabalho a menores de 16 anos (salvo aprendizes a partir de 14 anos); proteção legal de crianças e adolescentes; igualdade de direitos entre o trabalhador com vínculo empregatício e o trabalhador avulso; liberdade de associação profissional ou sindical do trabalhador; proibição (sem a expressa e prévia

Laborare. Ano II, Número 3, Jul-Dez/2019, pp. 60-80. ISSN 2595-847X. https://trabalhodigno.org/laborare DOI: https://doi.org/10.33637/2595-847x.2019-34 
anuência do trabalhador) de cobrança ou desconto salarial estabelecidos em instrumento coletivo de trabalho; direito de greve e de decidir quando exercê-lo; definição dos serviços ou atividades essenciais; disposições legais sobre o atendimento das necessidades inadiáveis da comunidade em caso de greve; tributos e outros créditos de terceiros; e as disposições previstas nos arts. 373-A, 390, 392, 392-A, 394, 394-A, 395, 396 e 400 da CLT.

Ainda, o parágrafo único do art. 611-B da CLT determina que as regras sobre duração do trabalho e intervalos não são consideradas normas de saúde, higiene e segurança do trabalho.

Cassar (2018, p. 1247) considera que:

A prevalência do negociado sobre o legislado enfraquece o princípio da indisponibilidade dos direitos legais trabalhistas, assim como derruba o princípio da prevalência da norma mais favorável. Torna os direitos trabalhistas menos públicos e mais privados, transformando a maioria dos direitos contidos na CLT, que não se encontram na Constituição, em direitos disponíveis, de característica privada.

A Lei $\mathrm{n}^{\mathrm{o}} 13.467 / 2017$ mitigou o princípio da norma mais favorável ao dissociar expressamente as normas da duração da jornada laboral das normas de saúde e segurança do trabalho, podendo aquelas ser objeto de negociação coletiva e prevalecerem sobre normas trabalhistas mais favoráveis aos obreiros.

Martins (2018) destaca que as hipóteses do art. 611-A da CLT são exemplificativas, pois se utiliza a expressão entre outros.

Se há uma regra na lei e outra no instrumento coletivo de trabalho, e a norma que prevalecerá será a menos benéfica em resultado de uma negociação coletiva, constata-se que o princípio da norma mais favorável deixou de ser imperativo no Direito do Trabalho e que a reforma trabalhista não observou o princípio da norma mais favorável ao trabalhador, por meio da Lei $\mathrm{n}^{0} 13.467 / 2017$.

Registrem-se, adicionalmente, algumas regras a serem observadas em decorrência da negociação coletiva, nos termos dos parágrafos do art. 611-A da CLT:

$\S 1^{\circ}$ No exame da convenção coletiva ou do acordo coletivo de trabalho, a Justiça do Trabalho observará o disposto no $\S 3^{\circ}$ do art. $8^{\circ}$ desta Consolidação. $\S^{\circ} \mathrm{A}$ inexistência de expressa indicação de contrapartidas recíprocas em convenção coletiva ou acordo coletivo de trabalho não 
ensejará sua nulidade por não caracterizar um vício do negócio jurídico. $\S 3^{\circ}$ Se for pactuada cláusula que reduza o salário ou a jornada, a convenção coletiva ou o acordo coletivo de trabalho deverão prever a proteção dos empregados contra dispensa imotivada durante o prazo de vigência do instrumento coletivo. $\S 4^{\circ} \mathrm{Na}$ hipótese de procedência de ação anulatória de cláusula de convenção coletiva ou de acordo coletivo de trabalho, quando houver a cláusula compensatória, esta deverá ser igualmente anulada, sem repetição do indébito. $\S 5^{\circ}$ Os sindicatos subscritores de convenção coletiva ou de acordo coletivo de trabalho deverão participar, como litisconsortes necessários, em ação individual ou coletiva, que tenha como objeto a anulação de cláusulas desses instrumentos.

A Lei $\mathrm{n}^{\mathrm{o}} 13.467 / 2017$ prestigiou o princípio da intervenção mínima na autonomia da vontade coletiva. Não obstante, a partir de análise da aplicação das normas jurídicas (NASCIMENTO; NASCIMENTO, 2018), surge o questionamento se a Constituição é a norma que está no topo de todo o ordenamento jurídico. Para os autores, é nítido que sim, porquanto à Constituição é atribuída o papel basilar da unidade do sistema, não podendo normas inferiores contrariarem ou revogarem leis constitucionais também nas relações de trabalho.

Entretanto, há um ponto específico ao Direito do Trabalho, pois este campo jurídico tem uma finalidade que o difere do Direito Comum. No ramo justrabalhista (NASCIMENTO; NASCIMENTO, 2018, p. 133):

O objetivo maior é social, a promoção da melhoria das condições sociais do trabalhador, daí a própria União, que tem competência para legislar sobre a matéria, permitir, salvo exceções que ressalva, que normas e condições mais vantajosas para os assalariados, conferindo direitos acima dos que previu na Constituição, venham a ser criadas pelas normas inferiores do escalonamento.

É justamente essa característica do Direto do Trabalho que determina a formação do princípio da norma mais favorável ao trabalhador, cuja importância foi reduzida com a reforma trabalhista. Constata-se que a Lei $n^{\circ} 13.467 / 2017$ não observa também a Constituição e repercute direta e desfavoravelmente na proteção ao trabalhador.

Ante o exposto, percebe-se que a reforma trabalhista inobservou a Constituição e a lógica do princípio da norma mais favorável ao trabalhador, própria do ramo justrabalhista, tanto na elaboração como na aplicação e interpretação normativa. 


\section{Inobservância do princípio do in dubio pro operario}

O princípio do in dubio pro operario ou in dubio pro misero, como estudado, relaciona-se com a forma de interpretação da lei, vinculando o intérprete, em caso de regra que permita escolher entre duas ou mais interpretações, àquela que se mostre mais favorável ao trabalhador.

Registre-se a antiga redação do parágrafo único do art. $8^{\circ}$ da CLT: "O direito comum será fonte subsidiária do direito do trabalho, naquilo em que não for incompatível com os princípios fundamentais deste”. Em seguida, há a redação do novo $\S 1^{\circ}$, do art. $8^{\circ}$ da CLT: "O direito comum será fonte subsidiária do direito do trabalho".

A antiga norma privilegiava a aplicação dos princípios fundamentais do Direito do Trabalho em detrimento das normas do Direito Comum. Com a supressão do trecho "naquilo em que não for incompatível com os princípios fundamentais deste", o privilégio dos princípios trabalhistas frente ao Direito Comum deixa de existir.

Após a reforma trabalhista, o Direito Comum pode ser utilizado subsidiariamente pelas autoridades administrativas e pela Justiça do Trabalho nas suas interpretações, com prioridade sobre os princípios do Direito do Trabalho. A supressão mencionada demonstra que não há mais prevalência dos princípios do Direito do Trabalho frente ao Direito Comum.

Em adição, vejam-se os novos $\S \S 2^{\circ}$ e $3^{\circ}$ do art. $8^{\circ}$ da CLT.

$\S 2^{\circ}$ Súmulas e outros enunciados de jurisprudência editados pelo Tribunal Superior do Trabalho e pelos Tribunais Regionais do Trabalho não poderão restringir direitos legalmente previstos nem criar obrigações que não estejam previstas em lei. $\S 3^{\circ}$ No exame de convenção coletiva ou acordo coletivo de trabalho, a Justiça do Trabalho analisará exclusivamente a conformidade dos elementos essenciais do negócio jurídico, respeitado o disposto no art. 104 da Lei $\mathrm{n}^{\circ} 10.406$, de 10 de janeiro de 2002 (Código Civil), e balizará sua atuação pelo princípio da intervenção mínima na autonomia da vontade coletiva.

A reforma trabalhista privilegiou a mínima intervenção da Justiça na análise dos instrumentos coletivos, estabelecendo que o judiciário verifique apenas a conformidade do negócio jurídico definido no Código Civil, que, em essência, supõe a igualdade das partes. 


\section{Eduardo Baptista Vieira}

Verifica-se que o legislador coibiu interpretações que extrapolem a lei em sentido estrito, como aquelas interpretações que utilizem princípios do Direito do Trabalho, a exemplo do princípio do in dubio pro operario e do princípio protetivo.

Constata-se, destarte, que a reforma trabalhista não prestigiou o princípio do in dubio pro operário e reduziu a proteção ao trabalhador.

\section{Inobservância da condição mais favorável ao trabalhador}

A reforma trabalhista desprestigiou o princípio da condição mais favorável, sobretudo quanto ao entendimento do direito adquirido, insculpido no XXXVI do art. $5^{\circ}$ da Constituição e no art. 468 da CLT (CASSAR, 2017).

Para Cassar (2018), a reforma trabalhista não observou corretamente o princípio da condição mais favorável, revestido de direito adquirido, ao permitir alterações como a resultante de ajuste escrito entre as partes para o trabalho telepresencial (afastando regras da duração do trabalho) ou a reversão unilateral do trabalho telepresencial para presencial. Igualmente, ao permitir a redução de direitos de empregados portadores de diploma de curso superior, que ganhem salário igual ou maior que o dobro do máximo benefício previdenciário; a modificação de contratos integrais para intermitentes; a reversão, com supressão do adicional, de gratificação de função de confiança para empregados que exercem a função há mais de 10 anos; ou a redução de benesses contratuais, por meio da negociação coletiva.

Cassar (2017) pontua que a inclusão do parágrafo no art. 444 da CLT, que flexibiliza a negociação entre empresas e empregados portadores de diploma de nível superior, que percebam salário igual ou superior a duas vezes ao limite máximo do benefício do Regime Geral da Previdência Social, deve, nos termos do art. 611-A da CLT, atrair regras trabalhistas menos favoráveis aos obreiros do que as regras da CLT ou previstas em instrumentos coletivos de trabalho.

Delgado (2018, p. 1209), ainda, ao analisar o poder diretivo da empresa, destaca a amplitude dada a esse poder pela Lei $n^{\circ} 13.467 / 2017$ :

A Lei da Reforma Trabalhista alargou os poderes empresariais já significativamente extensos no contrato de adesão empregatício, ampliando o espaço para a atuação do jus variandi empresarial. Grande parte das vezes, porém, astutamente, o fez mediante novas permissões legais para a "livre estipulação" contratual, sem tomar em conta estar-se diante de um dos mais acentuados contratos de adesão existentes na sociedade e economia capitalistas (nesta linha, o disposto no novo parágrafo único do art. 444 da CLT).

Laborare. Ano II, Número 3, Jul-Dez/2019, pp. 60-80. ISSN 2595-847X. https://trabalhodigno.org/laborare DOI: https://doi.org/10.33637/2595-847x.2019-34 
Cassar (2017) afirma que uma das repercussões da reforma trabalhista no princípio da condição mais favorável foi imposta pela redação do $\S^{\circ} 3$ do art. 614 da CLT, qual seja, "não será permitido estipular duração de convenção coletiva ou acordo coletivo de trabalho superior a dois anos, sendo vedada a ultratividade".

Cassar (2017, p. 7) argumenta que foi instituído o princípio da "não incorporação definitiva das benesses normativas ao contrato de trabalho", porque a condição favorável ao trabalhador deixará de existir com a perda da vigência do instrumento coletivo ou com a supressão da vantagem por outra norma coletiva posterior.

Leite (2018, p. 825) ensina que, até 2012, a súmula 277 do TST definia que "as condições de trabalho previstas em sentença normativa, convenção coletiva ou acordo coletivo vigorariam no prazo definido, não integrando, de forma definitiva, os contratos individuais de trabalho". Esse entendimento alinhava-se à teoria da aderência limitada ao prazo de duração do instrumento coletivo de trabalho. Depois de 2012, a jurisprudência ajustou-se à teoria da aderência por revogação por norma coletiva ulterior, adotando a ultratividade das normas coletivas.

Leite (2018, p. 826) esclarece que, para a teoria da aderência por revogação, "as condições adquiridas por meio de norma coletiva não incorporam definitivamente o contrato individual de trabalho, porém continuam em vigor até que venha norma posterior dispondo de maneira diferente". Essa teoria está consagrada no $\$ 2^{\circ}$ do art. 114 da Constituição, alterado pela Emenda Constitucional no 45/04, que dispôs que a Justiça deverá respeitar "as condições mínimas legais de proteção ao trabalho, bem como as convencionadas anteriormente".

Portanto, antes da reforma trabalhista, as decisões judiciais estavam vinculadas à súmula 277 do TST, ou seja, "as cláusulas normativas dos acordos coletivos ou convenções coletivas integram os contratos individuais de trabalho e somente poderão ser modificadas ou suprimidas mediante negociação coletiva de trabalho".

Segundo Martins (2018), a questão da ultratividade dependerá do Supremo Tribunal Federal - STF, ou melhor, do julgamento da súmula 277 do TST. Caso o STF entenda que a ultratividade está no $\S 2^{\circ}$ do art. 114 da $\mathrm{CF} / 88$, o dispositivo celetista será determinado inconstitucional. Caso contrário, não havendo norma coletiva vigente, as cláusulas de normas anteriores não deverão ser incorporadas aos contratos de trabalho. Registre-se que, em decisão liminar, o Ministro do STF, Gilmar Mendes, entendeu não haver base legal ou constitucional para a súmula 277 do TST, determinando, na ADPF 323, a suspensão dos efeitos e processos em curso sobre a ultratividade de acordos e de convenções coletivas. 


\section{Eduardo Baptista Vieira}

Não obstante, de acordo com a reforma trabalhista, não há mais ultratividade dos instrumentos coletivos, estando o princípio da condição mais favorável impactado neste quesito, consequentemente, o princípio da proteção ao trabalhador.

Com efeito, verifica-se que a reforma trabalhista inobservou e alterou o alcance da prevalência do princípio da condição mais favorável ao trabalhador no âmbito justrabalhista, haja vista a suavização da aplicação principiológica do direito adquirido, a possibilidade de retirada de direitos por meio da negociação coletiva, a criação de novas formas de contratos mediante a livre pactuação entre as partes, o aumento do poder diretivo do empregador e a modificação da regra da ultratividade dos instrumentos coletivos de trabalho.

\section{CONCLUSÃO}

Os princípios são as razões da existência de uma estrutura normativa, ou seja, são as ideias fundantes do ordenamento jurídico, cujas regras jurídicas devem estar vinculadas para que possam cumprir as suas finalidades. Consequentemente, os princípios devem pautar a criação de normas jurídicas e contratuais, bem como a interpretação e a aplicação do Direito.

No caso do Direito do Trabalho, o princípio da proteção ao trabalhador eleva-se como o mais importante porque é o princípio que melhor traduz a raiz sociológica justrabalhista da proteção social dos trabalhadores.

A reforma trabalhista, promovida pelo Estado brasileiro em 2017, não observou a principiologia de proteção ao trabalhador, característica do Direito do Trabalho, afastando-se da finalidade de proteção social dos trabalhadores inerente ao ramo justrabalhista.

A Lei ${ }^{\circ} 13.467 / 2017$ inobservou o princípio da proteção ao trabalhador no âmbito do princípio da norma mais favorável ao trabalhador, na esfera do princípio da condição mais benéfica ao trabalhador e dentro da lógica do in dubio pro operario.

Constatou-se o grande espaço aberto à negociação coletiva. A prevalência do negociado sobre o legislado enfraqueceu a indisponibilidade dos direitos trabalhistas, tornando-os mais privados, e reduziu a proteção dos trabalhadores.

Em decorrência da negociação coletiva, o princípio da proteção ao trabalhador deixou de ser imperativo no Direito do Trabalho, haja vista uma norma menos vantajosa ao empregado poder prevalecer no interior do contrato de trabalho. 
A intenção do legislador reformista de condicionar o poder judiciário a intérprete da norma coletiva, e não da norma constitucional e das leis, também diminuiu a proteção ao trabalhador.

A Lei $\mathrm{n}^{0} 13.467 / 2017$ desconsiderou o princípio da condição mais benéfica e, consequentemente, diminuiu a abrangência da proteção ao trabalhador no Direito do Trabalho, seja em decorrência das negociações coletivas ou da mudança da regra da ultratividade dos instrumentos coletivos de trabalho.

A reforma trabalhista não observou corretamente o princípio da proteção ao trabalhador, típico do Direito do Trabalho. A reforma foi concebida sem aderência à principiologia do Direito Trabalhista quando não prestigiou a proteção ao trabalhador, criando uma estrutura que permite reduzir, em regra, direitos dos trabalhadores.

A reforma trabalhista não está em absoluta sintonia com o comando constitucional que prescreve os direitos dos trabalhadores urbanos e rurais, além de outros que visem à melhoria da condição social dos obreiros. Portanto, é inconstitucional em alguns pontos. A edição de regras trabalhistas deve resultar na melhoria da condição socioeconômica dos trabalhadores, conforme caput do art. $7^{\circ}$ da Constituição.

A Lei $\mathrm{n}^{\mathrm{o}} 13.367 / 2017$ não observou adequadamente princípios protetivos e constitucionais, permitiu a supressão de regras benéficas ao trabalhador, priorizou a aplicação de norma menos favorável ao empregado, valorizou a livre autonomia da vontade e a prevalência do negociado sobre o legislado.

A reforma trabalhista modificou a essência do Direito do Trabalho e foi de encontro ao projeto civilizatório, humanístico e social proposto pela Constituição do Brasil.

\section{REFERÊNCIAS}

Barros, Alice Monteiro de. (2010). Curso de Direito do Trabalho. 6. ed. rev e ampl. São Paulo: LTr.

Brasil. Constituição da República Federativa do Brasil. Constituição (1988). Disponível em: http://www.planalto.gov.br/ccivil_03/Constituicao/Constituicao.htm. Acesso em: 09 fev. 2019.

Brasil. Decreto-Lei 5.452, de $1^{\circ}$ de maio de 1943. Aprova a Consolidação das Leis do Trabalho. Disponível em: http://www.planalto.gov.br/ccivil_03/Decreto-Lei/Del5452.htm. Acesso em: 18 jan. 2019. 


\section{Eduardo Baptista Vieira}

Brasil. Instituto Brasileiro de Geografia e Estatística. Indicadores IBGE. Pesquisa Nacional por Amostra de Domicílios Contínua. Trimestre Móvel Set. - Nov. 2018. Disponível https://biblioteca.ibge.gov.br/visualizacao/periodicos/3086/pnacm_2018_nov.pdf. Acesso em: 30 jan. 2019.

Brasil. Lei $n^{\circ}$ 6.019, de 3 de janeiro de 1974. Dispõe sobre o Trabalho Temporário nas Empresas Urbanas, e dá outras Providências. Disponível em: www.planalto.gov.br/ccivil_03/leis/L6019.htm. Acesso em: 11 nov. 2018.

Brasil. Lei 10.406, de 10 de janeiro de 2002. Institui o Código Civil. Disponível em: http://www.planalto.gov.br/ccivil_03/LEIS/2002/L10406.htm. Acesso em: 09 fev. 2019.

Brasil. Lei $n^{\circ} 13.467$, de 13 de julho de 2017. Altera a Consolidação das Leis do Trabalho (CLT), aprovada pelo Decreto-Lei no 5.452, de 1o de maio de 1943, e as Leis nos 6.019, de 3 de janeiro de 1974, 8.036, de 11 de maio de 1990, e 8.212, de 24 de julho de 1991, a fim de adequar a legislação às novas relações de trabalho. Disponível em http://www.planalto.gov.br/ccivil_03/_Ato2015-2018/2017/Lei/L13467.htm. Acesso em: 18 jan. 2019.

Brasil. Supremo Tribunal Federal. Arguição de Descumprimento de Preceito Fundamental $323 . \quad$ Disponível em: http://www.stf.jus.br/arquivo/cms/noticianoticiastf/anexo/adpf323.pdf. Acesso em: 13 fev. 2019.

Brasil. Tribunal Superior do Trabalho. Súmulas da Jurisprudência Uniforme do Tribunal Superior do Trabalho. Disponível em: http://www.tst.jus.br/sumulas. Acesso em: 09 fev. 2019.

Brasil. Tribunal Superior do Trabalho. Súmulas Orientações Jurisprudenciais (Tribunal Pleno/Órgão Especial, SBDI-I, SBDI-I Transitória, SBDI-II e SDC), Precedentes Normativos. Disponível em: http://www.tst.jus.br/documents/10157/63003/LivroInternet.pdf. Acesso em: 11 nov. 2018.

Cairo Júnior, José. (2012). Curso de Direito Processual do Trabalho. 5. ed. Salvador: JusPODIVM.

Cassar, Vólia Bomfim; Borges, Leonardo Dias. (2017). Comentários à Reforma Trabalhista. Rio de Janeiro: Forense; São Paulo: Método.

Cassar, Vólia Bomfim. (2014). Direito do Trabalho. 9. ed. rev. e atual. Rio de Janeiro: Forense; São Paulo: Método. 
Cassar, Vólia Bomfim. (2018). Direito do Trabalho: de acordo com a reforma trabalhista Lei 13.467. 15. ed. rev., atual. e ampl. Rio de Janeiro: Forense; São Paulo: Método.

Delgado, Maurício Godinho. (2014). Curso de direito do trabalho. 13. ed. São Paulo: LTr.

Delgado, Maurício Godinho. (2018). Curso de direito do trabalho. 17. ed. rev. atual. e ampl. - São Paulo: Ltr.

Leite, Carlos Henrique Bezerra. (2018). Curso de Direito do Trabalho. 10. ed. São Paulo: Saraiva Educação.

Martins, Sergio Pinto. (2014). Comentários à CLT. 18. ed. São Paulo: Atlas.

Martins, Sergio Pinto. (2014). Direito do Trabalho. 30. ed. - São Paulo: Atlas.

Martins, Sergio Pinto. (2018). Reforma Trabalhista: comentários às alterações das Leis n. 13.467/2017, 13.545/2017 e da Medida Provisória n. 808/2017. São Paulo: Saraiva Educação.

Nahas, Thereza. (2017). O novo direito do trabalho: institutos fundamentais impactos da reforma. São Paulo: Editora Revista dos Tribunais.

Nascimento, Amauri Mascaro. (2014). Iniciação ao direito do trabalho. 39. ed. São Paulo: LTr.

Nascimento, Amauri Mascaro; Nascimento, Sônia Mascaro. (2018). Iniciação ao Direito do Trabalho. 41. ed. São Paulo: LTr.

Sussekind, Arnaldo. (2002). Curso de Direito do Trabalho. Rio de Janeiro: Renovar.

Recebido: 16/06/2019

Revisado: 11/08/2019

Aprovado: 07/10/2019 